This item was submitted to Loughborough's Research Repository by the author.

Items in Figshare are protected by copyright, with all rights reserved, unless otherwise indicated.

\title{
The thermal effect of internal exhaust gas recirculation on controlled auto ignition
}

PLEASE CITE THE PUBLISHED VERSION

http://www.sae.org/congress/2003/

PUBLISHER

(C) SAE International

VERSION

VoR (Version of Record)

LICENCE

CC BY-NC-ND 4.0

REPOSITORY RECORD

Chen, Rui, Nesa Milovanovic, J.W.G. Turner, and D. Blundell. 2011. "The Thermal Effect of Internal Exhaust Gas Recirculation on Controlled Auto Ignition”. figshare. https://hdl.handle.net/2134/8404. 
This item was submitted to Loughborough's Institutional Repository (https://dspace.lboro.ac.uk/) by the author and is made available under the following Creative Commons Licence conditions.

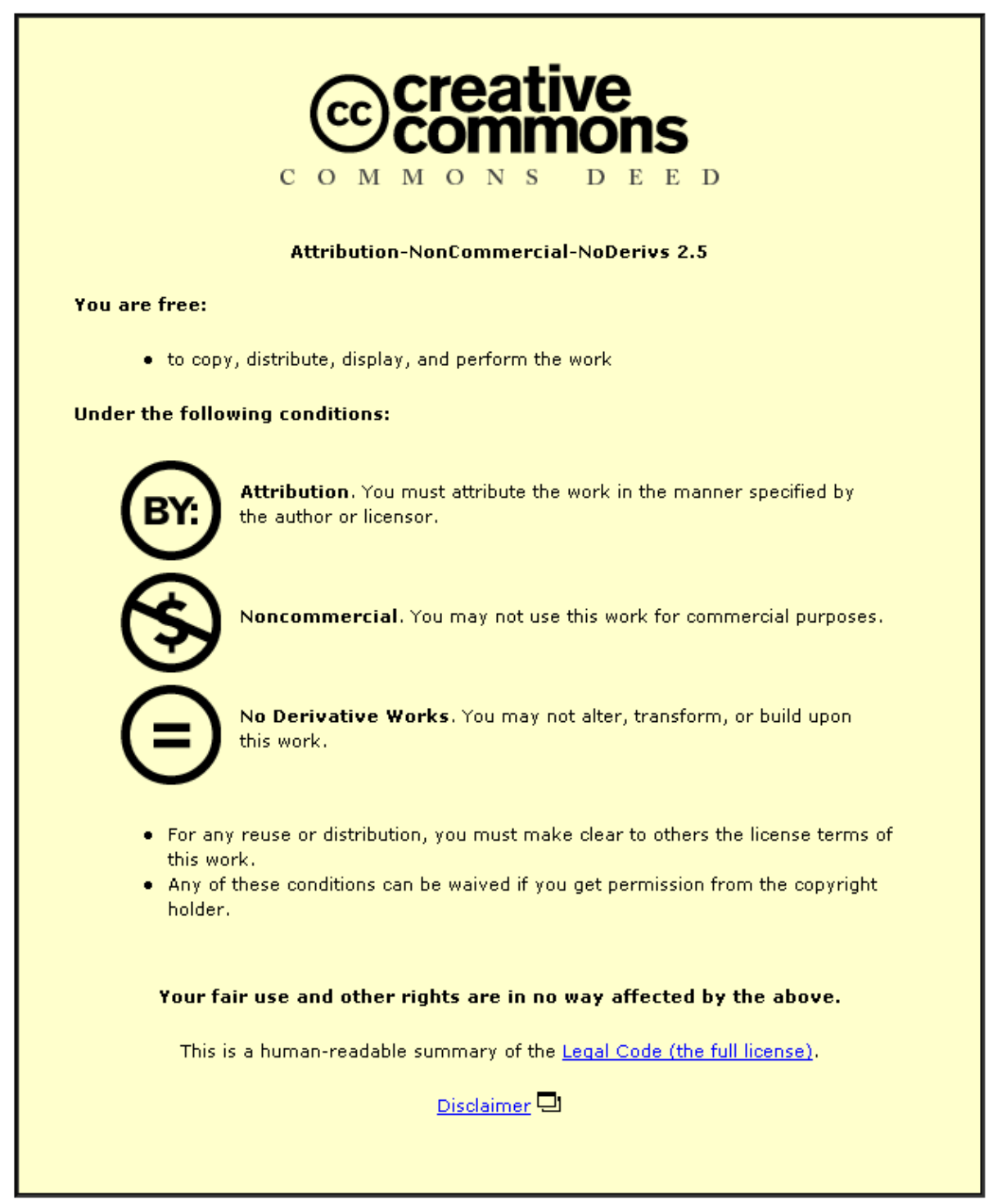

For the full text of this licence, please go to: http://creativecommons.org/licenses/by-nc-nd/2.5/ 


\section{The Thermal Effect of Internal Exhaust Gas Recirculation on Controlled Auto Ignition}

Rui Chen and Nebojsa Milovanovic Department of Aeronautical \& Automotive Engineering, Loughborough University

Jamie Turner and Dave Blundell Powertrain Research Department, Lotus Engineering

Reprinted From: Homogeneous Charge Compression Ignition (HCCl) Combustion 2003

(SP-1742) 
All rights reserved. No part of this publication may be reproduced, stored in a retrieval system, or transmitted, in any form or by any means, electronic, mechanical, photocopying, recording, or otherwise, without the prior written permission of SAE.

For permission and licensing requests contact:

SAE Permissions
400 Commonwealth Drive
Warrendale, PA 15096-0001-USA
Email: permissions @ sae.org
Fax: $724-772-4891$
Tel: $\quad 724-772-4028$

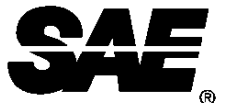

Global Mobility Database ${ }^{\ominus}$

All SAE papers, standards, and selected books are abstracted and indexed in the Global Mobility Database.

For multiple print copies contact:

SAE Customer Service

Tel: $\quad$ 877-606-7323 (inside USA and Canada)

Tel: $\quad$ 724-776-4970 (outside USA)

Fax: $\quad$ 724-776-1615

Email: CustomerService@sae.org

\section{ISSN 0148-7191}

\section{Copyright $\odot 2003$ SAE International}

Positions and opinions advanced in this paper are those of the author(s) and not necessarily those of SAE. The author is solely responsible for the content of the paper. A process is available by which discussions will be printed with the paper if it is published in SAE Transactions.

Persons wishing to submit papers to be considered for presentation or publication by SAE should send the manuscript or a 300 word abstract of a proposed manuscript to: Secretary, Engineering Meetings Board, SAE.

\section{Printed in USA}




\title{
The Thermal Effect of Internal Exhaust Gas Recirculation on Controlled Auto Ignition
}

\author{
Rui Chen and Nebojsa Milovanovic \\ Department of Aeronautical \& Automotive Engineering, Loughborough University \\ Jamie Turner and Dave Blundell \\ Powertrain Research Department, Lotus Engineering
}

Copyright @ 2003 SAE International

\begin{abstract}
Controlled Auto Ignition (CAI) uses compression heat to auto ignite a homogeneous air/fuel mixture. Using internal exhaust gas recirculation (IEGR) as an indirect control method, CAl offers superior fuel economy and pollutant emission reductions. Practically, this can readily be achieved by a method of early exhaust valve closure and late inlet valve opening to trap exhaust gas residuals within the cylinder from one cycle to the next. In order to understand the combustion mechanism, we did a comprehensive investigation on CAl fuelled with isooctane. Test data was gathered from a single cylinder research engine equipped with Lotus' Research Active Valve Train (AVT) System, and the modelling study was based on detailed chemical kinetics. It was found that CAl can only occur when the thermal energy of the engine charge, which is a mixture of air / fuel and IEGR, reaches a certain level. This thermal energy is inherited from IEGR trapped inside the cylinder from the previous combustion cycle, when the air / fuel fresh charge was supplied at ambient conditions.
\end{abstract}

\section{INTRODUCTION}

Controlled Auto Ignition (CAI) uses compression ignition to auto ignite a homogeneous air/fuel mixture. It therefore combines features of both $\mathrm{SI}$ and $\mathrm{Cl}$ combustion. Using internal exhaust gas recirculation (IEGR) as an indirect control method, CAl offers superior fuel economy and pollutant emission reductions. Practically, this can readily be achieved by a method of early exhaust valve closure and late inlet valve opening to trap exhaust gas residuals within the cylinder from one cycle to the next.

During the compression process, different parts of the charge mixture have different heat capacities due to local inhomogeneities which results in a non-unified temperature distribution throughout the combustion chamber. When the hotter parts reach their activation energies, combustion in these zones is initiated. The energy exotherm compresses the remainder of the charge, increasing the temperature, until full-scale ignition is established after a short time delay. Therefore, CAl combustion is a thermal environment-related autoignition process, but ignition itself is controlled by the chemical kinetics of the mixture with relatively little influence of turbulence and mixing. There is no largescale flame propagation.

In order to understand the combustion mechanism, we did a comprehensive investigation on CAl fuelled with iso-octane. Test data was obtained from a single cylinder research engine equipped with Lotus' Research Active Valve Train (AVT) System. The modelling study was based on detailed chemical kinetics. It was found that CAl can only occur when the thermal energy of the engine charge, which is a mixture of air / fuel and IEGR, reaches a certain level. This thermal energy is inherited from IEGR trapped inside the cylinder from the previous combustion cycle when the air / fuel fresh charge was supplied at ambient conditions.

\section{SIMULATION MODEL AND ENGINE TEST RIG}

COMBUSTION SIMULATION MODEL - The model used to simulate the CAl combustion in this research was the Aurora application from the Chemkin III combustion simulation package ${ }^{1}$. It considers the engine combustion chamber as a single-zone combustion reactor charged with a homogeneous mixture of air, fuel and residual burnt gas which has an evenly distributed chemical composition with uniform thermodynamic properties. The volume of the combustion chamber varied according to a slider-crank relationship. The heat loss was calculated using Woschni's heat transfer correlation ${ }^{2}$ with a temperature difference between the uniform gas temperature and the time averaged cylinder wall temperature. The other losses such as blowby, crevices volume and the existence of the boundary layer were not included. Consequently, the model over estimated the cylinder pressure, under predicted the combustion 
duration, and could not accurately predict $\mathrm{HC}$ and $\mathrm{CO}$ emissions. However, since the start of auto-ignition in CAl combustion is mainly a function of thermal and chemical conditions of the engine charge, the model can predict the start of auto-ignition with acceptable accuracy. In this investigation, a chemical kinetic mechanism of iso-octane combustion developed by $\mathrm{LLNL}^{3,4}$ was employed. It consists of 857 species and 3606 reactions. Each simulation started at the beginning of the compression stroke and finished at the end of expansion stroke, with a time step of $1^{\circ}$ crank angle. The temperatures of cylinder wall, piston and head were assumed to be $500 \mathrm{~K}$.

THERMODYNAMIC MIXING MODEL - The IEGR trapped inside the engine combustion chamber by the AVT system was assumed to be the equilibrium burned gas obtained from ${ }^{5}$

$$
\begin{aligned}
& \mathrm{C}_{8} \mathrm{H}_{18}+\varepsilon \lambda\left(\mathrm{O}_{2}+3.76 \mathrm{~N}_{2}\right) \rightarrow \\
& \mathrm{a}_{1} \mathrm{CO}_{2}+\mathrm{a}_{2} \mathrm{H}_{2} \mathrm{O}+\mathrm{a}_{3} \mathrm{~N}_{2}+\mathrm{a}_{4} \mathrm{O}_{2}+\mathrm{a}_{5} \mathrm{CO}+\mathrm{a}_{6} \mathrm{H}_{2}
\end{aligned}
$$

where $\varepsilon$ is the molar air-fuel ratio and $\lambda$ is the equivalent air to fuel ratio.

An equilibrium among the burned gases with a constant at the IEGR temperature of $T$ is assumed

$$
\begin{aligned}
& \mathrm{CO}_{2}+\mathrm{H}_{2} \Leftrightarrow \mathrm{CO}+\mathrm{H}_{2} \mathrm{O} \\
& \ln K(T)=2.743-\frac{1.761}{t}-\frac{1.611}{t^{2}}+\frac{0.2803}{t^{3}}
\end{aligned}
$$

where $t=T / 1000$.

The engine volumetric efficiency has been assumed to be $100 \%$ when no EGR is introduced. Therefore, the initial volume of the engine charge considered by the calculation is the volume occupied by the inlet fuel and air at ambient conditions.

When the IEGR is introduced, it occupies a certain proportion of the combustion chamber volume, $x$. Then the volume of IEGR is

$V_{E G R}=x V^{0}$ air/fuel

and the volume of air and fuel becomes

$V_{\text {air } / \text { fuel }}=(1-x) V^{0}$ air/ fuel

The mole quantity of the fuel, air and IEGR in the engine charge can then be obtained as

$n=\frac{P V}{R T}$ where the pressure, $P$, is 1atm for both IEGR and

air/fuel mixture, the temperature, $T$, for the air and fuel mixture is measured from engine test work, and the temperature of the IEGR varies according to the requirement of auto ignition.

After mixing the hot IEGR with the air and fuel mixture, the final temperature of the engine charge, which consists of air, fuel and IEGR at the beginning of the compression process, is calculated using the energy conservation equation,

$$
H_{m i x}=H_{\text {air/fuel }}+H_{E G R}
$$

The air to fuel equivalence ratio, $\lambda$, used throughout testing and calculations was the ratio between fresh air and fuel. The oxygen contained in the burned gas and reintroduced into the combustion chamber via IEGR was not considered.

TEST RIG - The engine employed in this research is a single cylinder, 4-stoke research engine based on a GM Family One 1.8litre series architecture. Figure 1 shows a photograph of the engine. It has a production piston and stroke, with a standard 4-cylinder head on top of a water cooled barrel to join the family one parts to the custom made bottom end. Only the front cylinder of the head is operational. The water jacket uses a combination of machined modifications and brackets. Unnecessary water transfer ports are blanked off. A Research AVT system is fitted to allow the variable valve timing strategy to be used to trap the predefined quantity of IEGR. The engine has a specially designed single cylinder bottom end to allow either pure combustion work or optical access versions to be built.

The use of conventional parts in the combustion system wherever possible ensures that the cost of rebuild is low in case of any component failures (because of uncontrolled detonation, for example). The compression ratio can easily be changed in this engine, both because of the separate barrel and, more importantly, because of the AVT system negating the need to consider modifications to belt runs etc. Any change in compression ratio is achieved by means of the deck height being moved up and down by spacers or special short liners, or a combination of the two. The bottom end can accept various strokes up to and including $100 \mathrm{~mm}$, and is capable of running to 7000rpm (depending on stroke). For this investigation, the compression ratio was set at 11:1.

The engine was connected to a Froude AG30 $30 \mathrm{~kW}$ eddy-current dynamometer. A redline ACAP data acquisition system from DSP Technologies Inc. was used, together with a Horiba MEXA 7100 DEGR emissions analyzer. Port fuel injection was used for the investigation, and the engine management system used 
was a conventional Lotus V8 engine controller. Isooctane was the fuel used throughout this investigation.

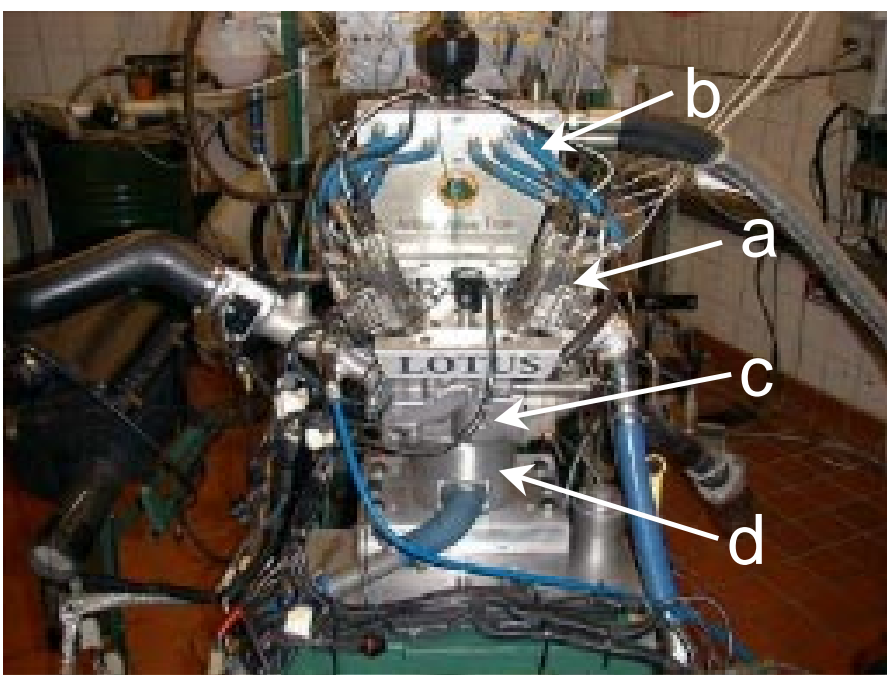

Fig. 1: Single-Cylinder Research Engine with AVT System: (a) Active Valve Train, (b) hydraulic system for AVT, (c) production cylinder head, (d) specially designed single cylinder bottom end

\section{VALVE EVENTS FOR CAI COMBUSTION}

The technique used to initiate and control CAI in this study is to trap a set quantity of exhaust gas using a very early exhaust valve closure (EVC) event coupled to a very late inlet valve opening (IVO) event. The general principle can be seen in Figure 2. The trapped exhaust gas is then compressed during the final stages of the exhaust stroke. As the piston descends on the induction stroke, the inlet valves are opened and the fresh charge is drawn into the cylinder partially filled with exhaust gas. At the end of the induction stroke, the inlet valves are closed and the fresh-charge and exhaust gas mixture compressed. CAl combustion occurs as the mixture ramps up in temperature in the final stages of the compression stroke. Once CAI has occurred, the power stroke drives the piston down and the cycle is repeated.
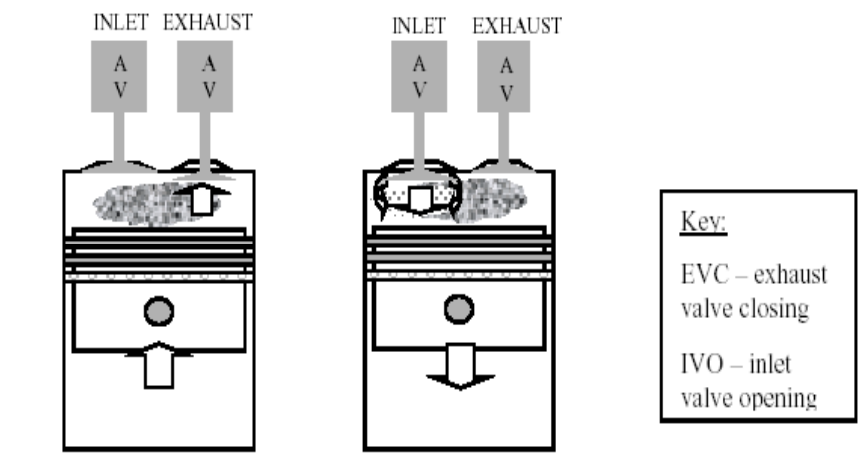

Eshasst Sircke - Earty EVC

Infuction Stroke-Lais IVO

Fig. 2: Valve Events suitable for CAI Combustion
In order to trap the IEGR, a series of valve events has been used. Figure 3 summaries the valve timing and estimated quantity of trapped IEGR. Four groups of valve settings have shown. Group 1 with $8 \mathrm{~mm}$ for exhaust valve lift and $8.5 \mathrm{~mm}$ for the inlet is the standard valve timing for SI combustion. In the rest of the groups, since a very early exhaust valve closure (EVC) event coupled to a very late inlet valve opening (IVO) event has been used to generate the CAl combustion, the valve lift has been reduced to $6 \mathrm{~mm}$ to reduce the valve dynamic loading to an acceptable level. Again, the reduced valve lifts can still be used for conventional SI combustion. This has been shown in the second group of valve profiles, where about $0-14 \%$ IEGR is trapped with slightly advanced EVC and retarded IVO. When the EVC is further advanced and IVO is further retarded to trap more IEGR, about 23 to $32 \%$ as shown in group 3, CAI combustion occurs but with slightly lean air/fuel mixture. This particular phenomenon will be addressed in a future publication.

In group 4, more IEGR, up to $74 \%$, has been trapped via a very early exhaust valve closure (EVC) event coupled to a very late inlet valve opening (IVO) event. CAI combustion could be initiated with these valve timings with the air to fuel ratio at stoichiometric conditions when the engine is fuelled with iso-octane. These are the timings used throughout this investigation.

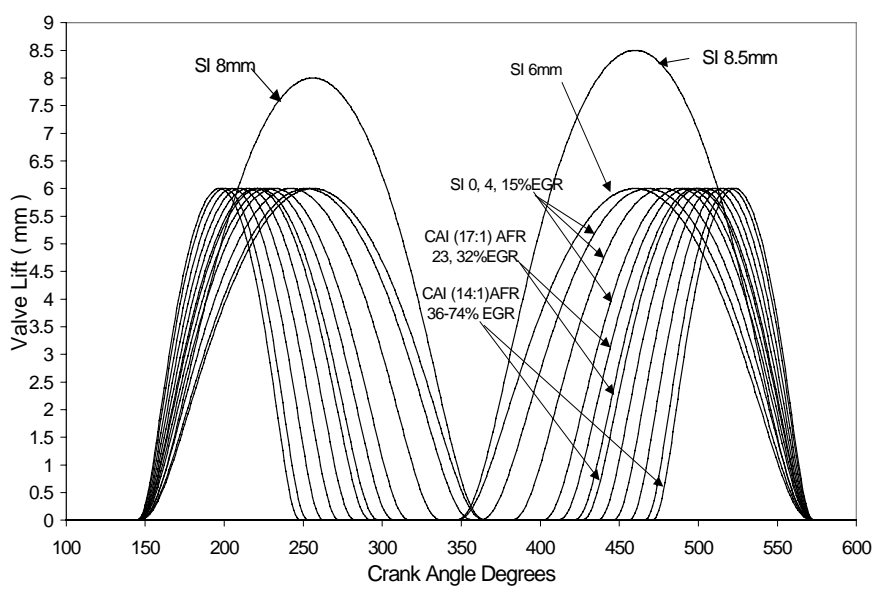

Fig. 3: Conventional SI Valve Profiles and Examples of Suitable Profiles for CAI

\section{RESULTS AND DISCUSSION}

Figure 4 shows the measured cylinder pressure traces. The engine speed during the test was maintained at 2000rpm. The $\lambda$ of fresh air and fuel mixture was 1 . Successful auto ignition has only been achieved with $59 \%$ and $55 \%$ of IEGR introduction, while with $50 \%$ to $32 \%$ IEGR introduction, spark is needed to assist the establishment of the combustion.

Figure 5 shows the peak cylinder pressure position with various IEGR introductions and the corresponding spark plug activation timings. In contrast to what is expected 
with conventional SI combustion, the peak pressure position appears to be influenced by the quantity of IEGR rather than the activation timing of the spark plug. This phenomenon can be recognized by comparing the cases of $36 \%$ of IEGR introduction with that of $32 \%$, and $50 \%$ IEGR introduction with that of $45 \%$. In the first comparison, the spark plug activation timing in both cases was 164degCA. The peak cylinder pressure advances by $3.5 \mathrm{deg} C A$ as IEGR increases. In the second comparison, the spark plug activation timing has been retarded by 1 degCA, but the peak cylinder pressure advances by 1 degCA. In the case of $55 \%$ and $59 \%$ of IEGR introduction, no spark plug activation was required for the initiation of combustion. Such results indicated that the activation of the spark plug did not function as an essential combustion source such as happens in a conventional SI combustion strategy, but as an assistance to improve auto ignition. When the quantity of IEGR was higher than a certain level, no such assistance was required, and pure auto ignition occur.

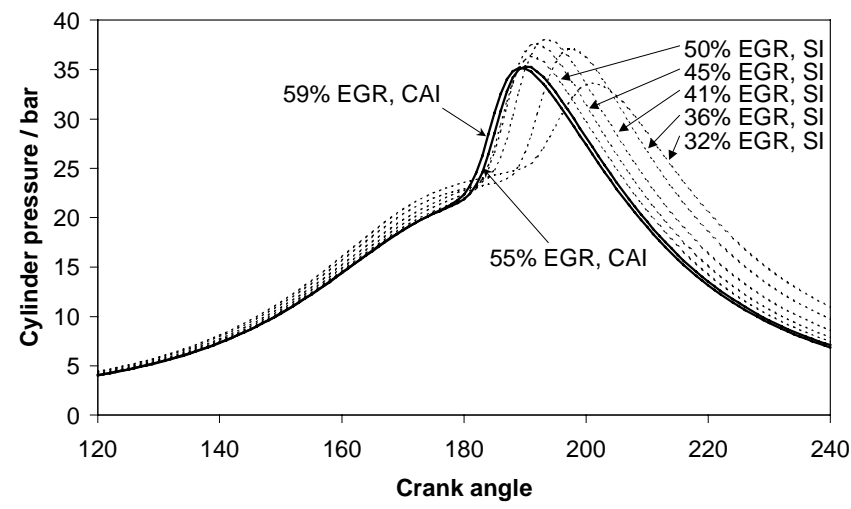

Fig. 4 Pressure Traces with Various Levels of IEGR Introduction

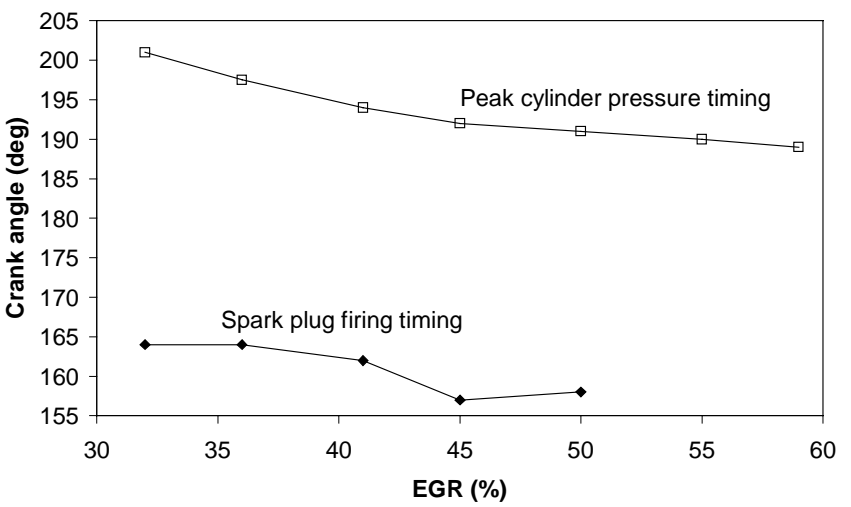

Fig. 5: Peak Cylinder Pressure Position and Spark Plug Activation Timing

Figure 6 shows the heat release rates with various IEGR introductions calculated from the experimental engine results shown in Figure 4. Figure 7 shows the peak heat release rate and its position with various IEGR introductions. It can be seen that the peak heat release rate position has a similar trend with the position of peak cylinder pressure against the quantity of IEGR introduction. The higher the level of IEGR introduction, the more advanced the peak heat release position. This confirms that the combustion obtained through the experiments are actually auto ignition based combustion; spark plug activation is only a help in establishing ignition when the quantity of IEGR is insufficient. On the other hand, the peak heat release rate increases as IEGR introduction reduces. This is simply due to the fact that the engine charge has been diluted by the introduced IEGR. The more IEGR being trapped inside the cylinder, the less intense the combustion can be, and the lower the peak heat release rate that can be achieved. However, in the case of $32 \%$ IEGR introduction, the peak heat release rate has largely been reduced. This signals a very delayed start of combustion timing.

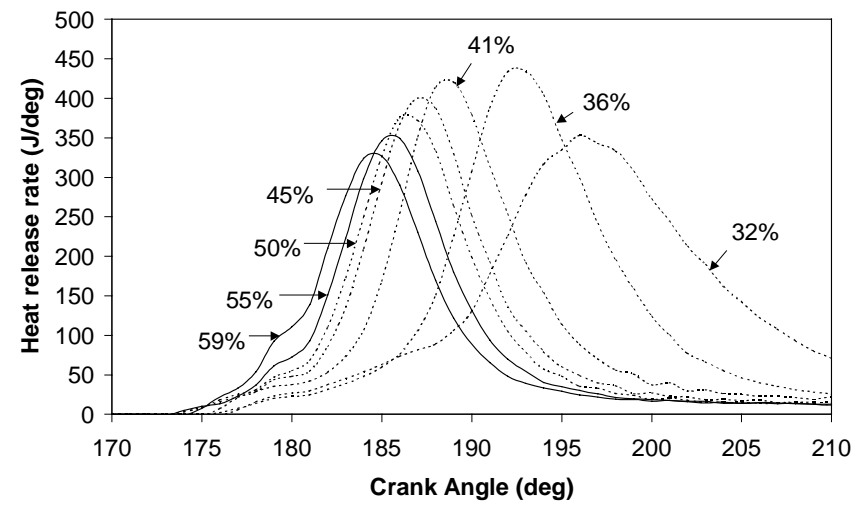

Fig. 6 Heat Release Rates with Various Levels of IEGR Introduction

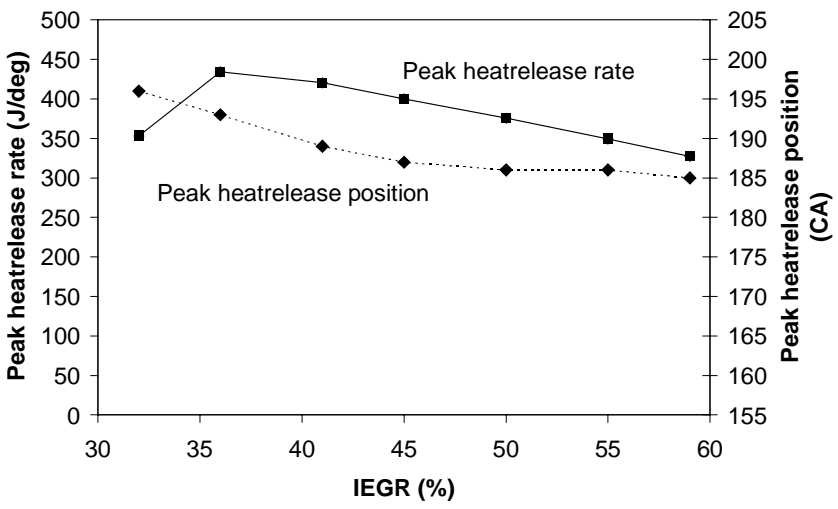

Fig. 7 Peak Heat Release Rates and Timing with Various Levels of IEGR Introduction

From the above experimental results, it appears that the combustion initiation timing and reaction rate obtained throughout the experimental investigation are largely dependent upon the quantity of the IEGR being trapped. The activation timing of the spark plug has little, if any, effect on it. In order to understand further the effect of the IEGR on the performance of combustion, a series of simulation analyze has been carried out.

Figure 8 shows a comparison between the measured and calculated cylinder pressure curves with $59 \%$ of IEGR introduction. The temperature of the air and fuel mixture during the test and input into the thermodynamic mixing model was $28^{\circ} \mathrm{C}$. To match the calculated 
pressure curve with the measured result as shown, the temperature of the engine charge, which consists of air, fuel and simulated IEGR at the beginning of the compression process, has to be $258^{\circ} \mathrm{C}$.

Comparing the two sets of results, a number of places where the calculated results do not agree well with the experimental results can be observed. Firstly, the calculated peak cylinder pressure is clearly over predicted. This is largely due to fact that the model did not consider engine blowby, crevices volume and the existence of the boundary layer.

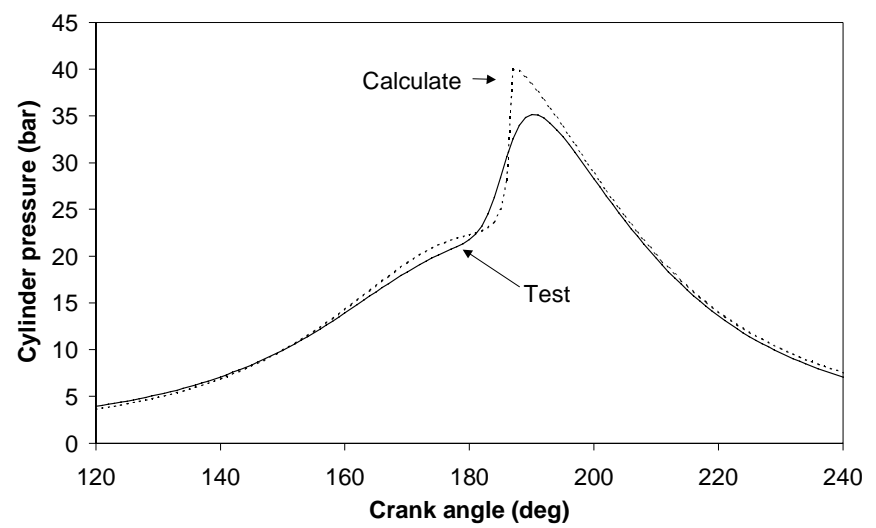

Fig. 8: Comparison between Measured and Calculated Cylinder Pressure with 59\% IEGR

Secondly, the peak pressure position has been advanced by the model. This is because the pressure increase rate obtained from the model is much higher than that from experiment. There are several possible reasons for this. (a) The IEGR used in the calculation was assumed to consist of burnt gas only. The chemical effect ${ }^{6}$ of the many species contained in the real IEGR has not been taken into account. (b) The entire engine was considered as a single-zone bulk gas at steady state with uniform thermal and chemical properties by the model, i.e. no gas motion has been considered. However, in reality the gas motion in-cylinder dominates the mixing of air, fuel and IEGR. Local inhomogeneities in the cylinder charge are to be expected. The areas with properties favouring auto ignition will ignite initially, then the rest of the engine charge follows. This will slow down the overall combustion reaction rate. (c) It has been noticed that the intensity of gas movement has a certain effect on the rate of combustion. This must also play a role in shifting the combustion reaction rate from the calculated results obtained at steady state.

Thirdly, the calculated cylinder pressure during the compression process is slightly higher than the measured value, especially during the period before the start of auto ignition. This may be due to the choice of improper heat transfer coefficients and cylinder wall temperatures for the heat release model.

Finally, and perhaps the most important difference, is that of temperature. To achieve the required engine charge temperature of $258^{\circ} \mathrm{C}$ at the beginning of the compression process, an IEGR temperature of $802^{\circ} \mathrm{C}$ is required. This is $355^{\circ} \mathrm{C}$ higher than the measured exhaust gas temperature. Again, there are reasons for this difference. (a) The experimental engine exhaust gas temperature is an average value measured in the exhaust port downstream of exhaust valve. There is a significant heat loss when hot burned gases are expelled into the exhaust port, which is surrounded by a relatively cool wall. Unlike the exhaust port, the cylinder wall has a much higher temperature. The heat loss from the bulk burned gas being trapped by the cylinder wall is relatively low. Therefore, the instantaneous temperature of the trapped burned gas at the beginning of the compression process should be much higher. Unfortunately, no facility was available during the test to record the instantaneous cylinder gas temperature. (b) The temperature of the air and fuel mixture is measured before it has been inducted into the cylinder. When the mixture is introduced into the combustion chamber, it has to flow at low speed over a number of hot surfaces such as the inlet port, the inlet valve and the hot cylinder wall. The actual temperature of the mixture at the time before the compression process is therefore much higher than the measured temperature used in the calculations.

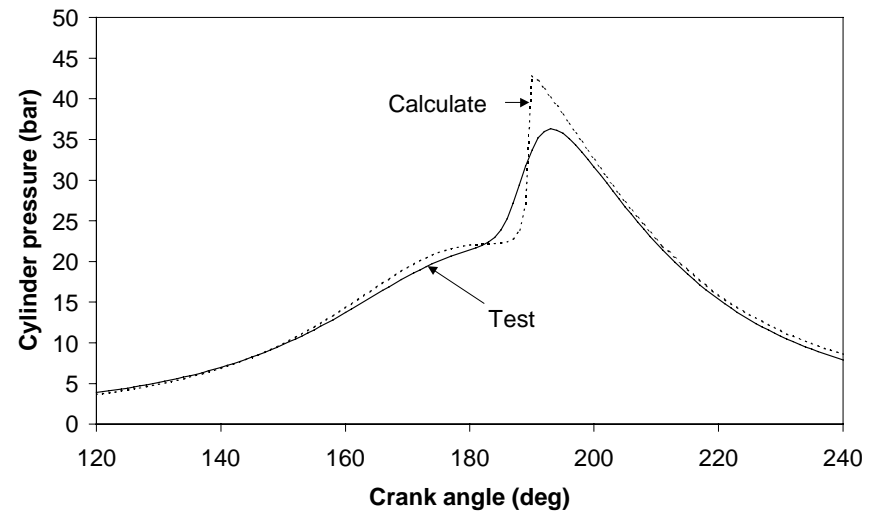

Fig. 9: Comparison between Measured and Calculated Cylinder Pressure Traces with 50\% IEGR

Figure 9 shows a comparison between the measured and calculated cylinder pressure curves with $50 \%$ IEGR. The temperature of the air and fuel mixture during the test and input into the model was $30^{\circ} \mathrm{C}$, and the measured average exhaust gas temperature downstream of the exhaust valve was $473^{\circ} \mathrm{C}$. To match the calculated pressure curve with the tested result shown, the temperature of the engine charge at the beginning of compression process has to be $245^{\circ} \mathrm{C}$.

Figure 8 and 9 shows a very similar effect between measured and calculated results. However, there is a fundamental difference between the two cases. In figure 8 , the combustion is pure CAI. In the case shown in Figure 9, the calculated results were for pure auto ignition, while the experimental results were obtained from spark assisted auto ignition combustion. Using the thermodynamic mixing model, we found that in order to 
reach the required engine charge temperature of $245^{\circ} \mathrm{C}$ at the beginning of the compression process with $50 \%$ of IEGR introduction, the IEGR temperature has to be as high as $1203^{\circ} \mathrm{C}$. This is $730^{\circ} \mathrm{C}$ higher than the measured average exhaust gas temperature downstream of the exhaust valve. Clearly, despite all of the assumptions made in the model, such a high IEGR temperature is not practically achievable. Therefore, a pure auto ignition with $50 \%$ IEGR introduction cannot occur. Combustion can only be initiated with assistance from the spark plug.

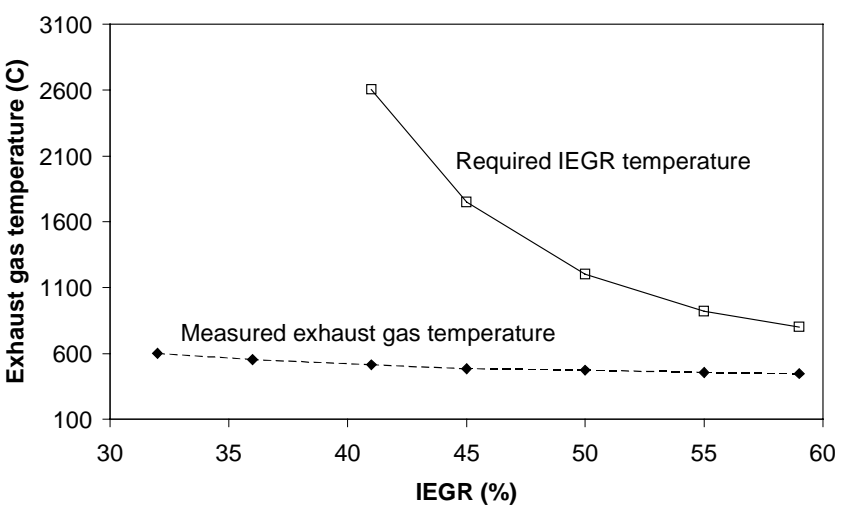

Fig. 10: Temperature of Measured Exhaust Gas and Calculated IEGR required for Pure CAI Combustion

Figure 10 shows the measure exhaust gas temperature and the calculated IEGR temperature required to start a pure auto ignition without the assistance of spark plug activation. It can be seen that when the quantity of IEGR introduction is lower than $55 \%$, the required temperature of the IEGR is well above $1200^{\circ} \mathrm{C}$. This is clearly not achievable practically. Therefore, the auto-ignited combustion can only occur when an additional source of higher temperature gas can be supplied. This has been done practically by activating the spark plug.

The spark plug contributes a fix quantity of thermal energy at a fixed temperature, which is about $10000^{\circ} \mathrm{C}$ to the charge mixture. In the case of conventional $\mathrm{SI}$ combustion, the thermal energy of the charge mixture is low, and auto ignition cannot occur. Combustion initiation relies on the spark plug and proceeds via flame propagation. Consequently, the EGR tolerance is much lower than that for auto-ignited combustion such as in the CAI case. However, with a high percentage of IEGR, the thermal state of the engine charge can be increased before spark plug activation. If the thermal state exceeds the fuel activation limit, auto ignition occurs without activating the spark plug. If the thermal state is high but below the limit, then the contribution from the spark plug becomes essential. However, with spark plug assistance, the combustion is still auto ignition based combustion. This is fundamentally different from spark initiated flame propagation combustion.

The hot IEGR trapped by the AVT system consists mainly of burnt gases at high temperature. Its effect on the ignition timing and the heat release rate of $\mathrm{CAl}$ combustion should, therefore, have two aspects ${ }^{8}$. One aspect of its effect is its high temperature. When the hot IEGR is mixed with the cool air/fuel mixture, it increases the temperature of the entire inlet charge, which helps the initiation of CAI combustion. This effect of the hot IEGR can be named the thermal effect. The other aspect of the effect of the trapped hot IEGR on CAI combustion is due to the different chemical species it contains. Different gaseous species have different thermal heat capacity profiles against temperature and chemical reactivities towards a combustion reaction. Their effect on cylinder temperature history and fuel auto-ignition should therefore be different. This aspect of the IEGR may be defined as the chemical effect. The above observed and calculated results should be a combination of these two.

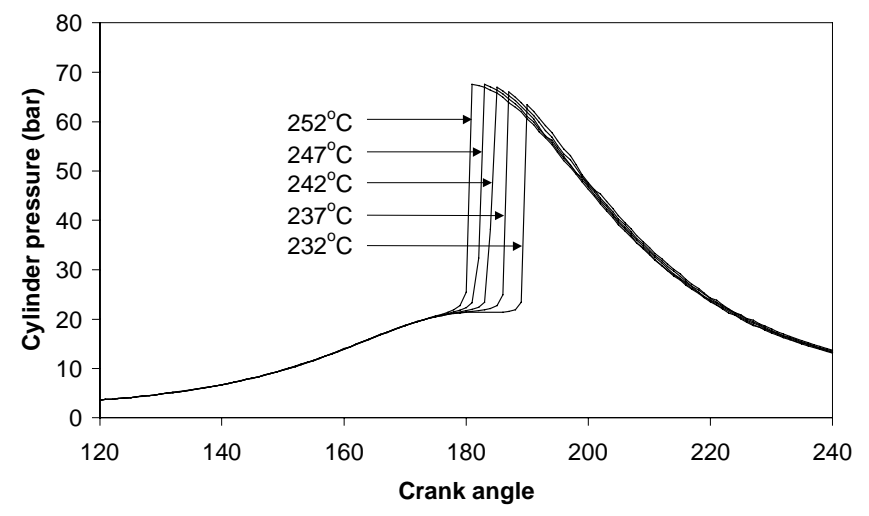

Fig. 11: Calculated Cylinder Pressure at Various Inlet Temperatures without IEGR

In order to eliminate the chemical effect from the IEGR, another series of calculations have been performed without the presence of IEGR. Figure 11 shows the calculated cylinder pressure traces at various charge temperatures, and Figure 12 shows the correlation between charge temperature and auto ignition timing from the calculated results. It can be seen that the higher the inlet charge temperature, the earlier the auto ignition occurs. To start the auto-ignition at the position around top dead centre, a temperature of $250^{\circ} \mathrm{C}$ is required. This is similar to the temperature of $258^{\circ} \mathrm{C}$ with $59 \%$ IEGR.

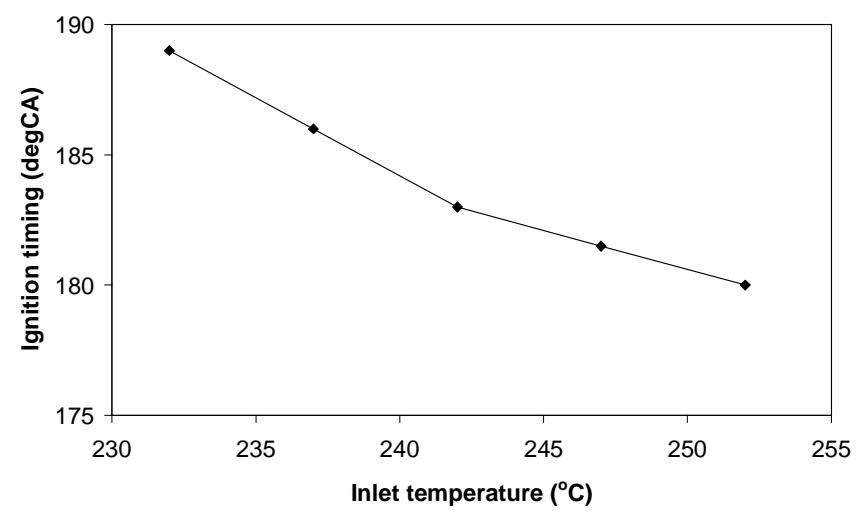

Fig. 12: Calculated Auto Ignition Timing at Various Inlet Temperature without IEGR Introduction 
Comparing the calculated results obtained with and without IEGR, it can be seen that the temperature requirements at the beginning of the compression process for pure auto ignition in both cases are very similar. This indicates that although there is a strong interference from the IEGR due to it various chemical species, a common thermal requirement to initiate the auto ignition exists. Below this level, no auto ignition occurs unless an external assistance can be supplied. The hot burnt gas trapped inside the combustion chamber contributes significantly in increasing the engine charge temperature, and establishes the very fundamental requirement - thermal environment - for the next cycle of auto ignition. The more IEGR trapped inside the combustion chamber, the higher the engine charge temperature is, and the earlier auto ignition occurs.

Figure 13 shows the measured exhaust gas temperature and the calculated engine charge temperature using the thermodynamic mixing model at the beginning of the compression process. It can be seen that although the exhaust gas temperature decreases as IEGR introduction increases due to the burnt gas dilution effect, the engine charge temperature actually increases since more hot gas has been introduced. This explains the observed phenomenon that more IEGR ensures pure auto ignition while less IEGR requires spark assistance.

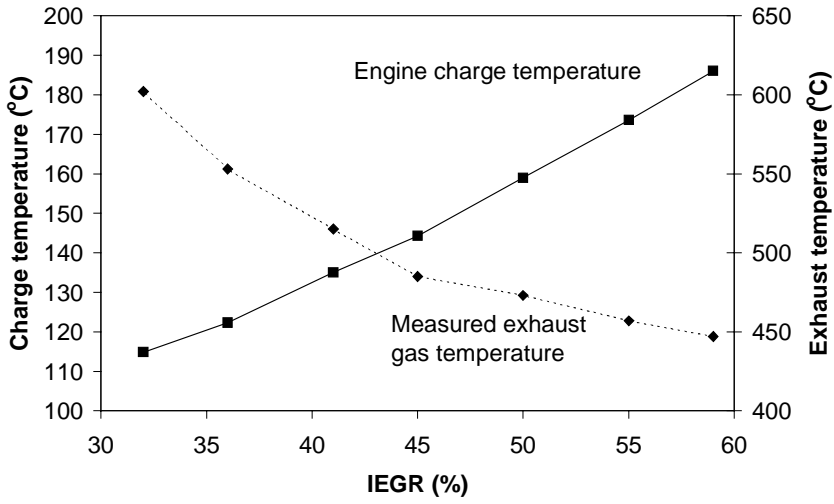

Fig. 13: Measured Engine Exhaust Gas Temperature and Calculated Charge Temperature with Various Levels of IEGR Introduction

Figure 14 shows the measured engine BMEP, IMEP and BSFC. Overall, engine BMEP output decreases as IEGR introduction increases. This is clearly due to the fact that a large portion of the engine swept volume has been occupied by the IEGR, therefore less fresh fuel and air can be burnt. Potentially, such results indicate that the engine power output can be directly controlled by regulating the introduction of IEGR using the AVT system. This offers an opportunity for a truly throttleless engine control. In line with the BMEP output, the IMEP is generally reduced with a higher percentage of IEGR. However, it is interesting to note that with a very high percentage of IEGR, when stable and pure auto ignition occurs, the IMEP increases. BSFC is generally increased as IEGR introduction increases.

Figure 15 shows the measured emission data at various IEGR. It can be seen that both THC and $\mathrm{CO}$ emissions increases as IEGR increases. On the other side, NOx emission reduces sharply as more IEGR is trapped. This may be due to the fact that the combustion temperature decreases as more IEGR is used. The low combustion temperature limits NOx production, but also reduces the oxidation reaction of the unburnt $\mathrm{HC}$ and $\mathrm{CO}$.

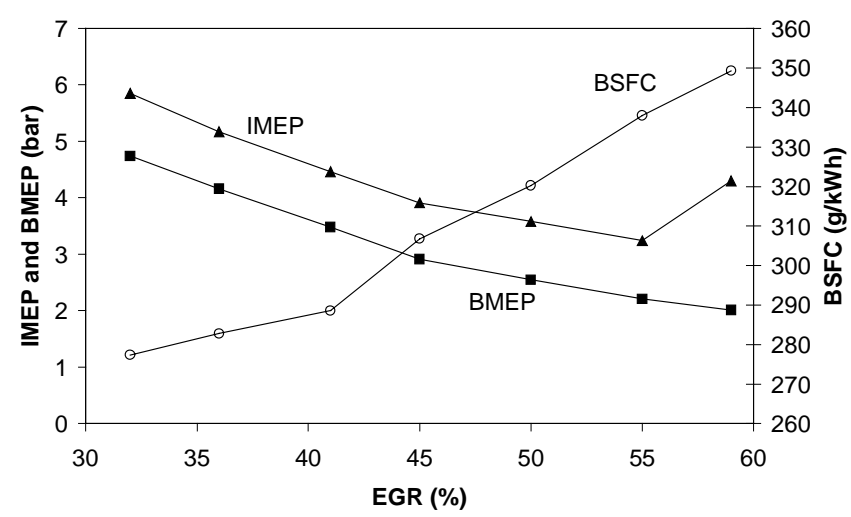

Fig. 14: Measured BMEP, IMEP and BSFC

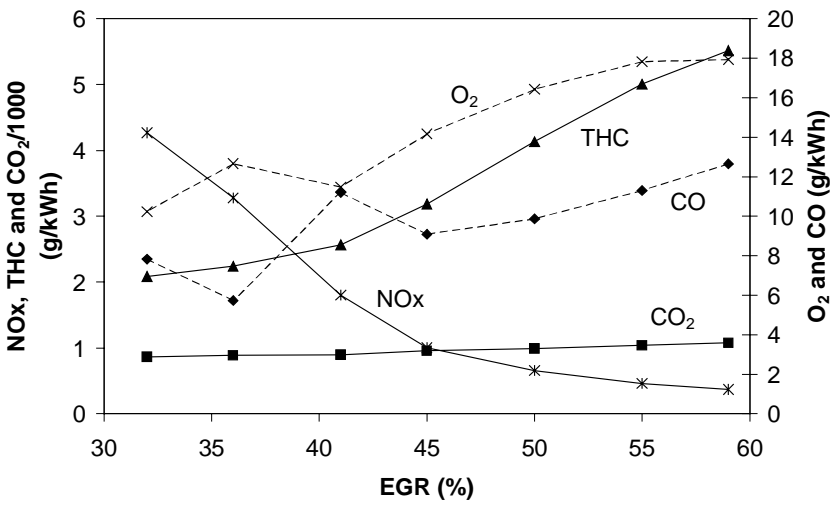

Fig. 15: Measured Specific Emission Data

\section{CONCLUSIONS}

The Aurora application from the Chemkin III combustion simulation package has been used to analyze the thermal effect of IEGR on CAI combustion.

An equilibrium burnt gas was used as the simulated IEGR during modelling studies. The temperature of the air, fuel and IEGR at the beginning of the compression process was calculated using the energy conservation equation.

It was found that pure auto-ignited CAI combustion can only be achieved with a certain amount of IEGR introduction. Below this level, assistance from the spark plug is needed for the establishment of auto ignition. 
With a high percentage of IEGR, although spark plug activation is required to initiate the combustion, the combustion is essentially auto-ignited combustion. Spark plug activation timing has little effect on the combustion event.

Although there is strong interference from IEGR due to its various chemical species, a common thermal requirement to initiate auto ignition exists. Below this level, no auto ignition occurs unless external assistance is supplied in the form of a spark event.

In four-stroke IC engines, although the exhaust gas temperature decreases as IEGR introduction increases due to the burnt gas dilution effect, the engine charge temperature actually increases since more hot gas has been introduced.

\section{REFERENCES}

1 Kee, R.J., et al "Chemkin-III: A Fortran Chemical Kinetics Package for The Analysis of Gas-Phase Chemical and Plasma Kinetics", Sandia National Laboratory, Report No. SAND96-8216.

${ }^{2}$ Woschni, G., "A Universally Applicable equation for the Instantaneous Heat Transfer Coefficient in the Internal Combustion Engine", SAE Paper 670931.

${ }^{3}$ Curran, H.J., et al., "A Comprehensive Modelling Study of iso-Octane Oxidation", Combustion and Flame, vol.129, pp 253-280, 2002.

${ }^{4}$ Curran, J., et al "Oxidation of Automotive Primary Reference Fuels at Elevated Pressures", Proceedings of the Combustion Institute $27^{\text {th }}, 379-387,1998$.

5 C. R. Ferguson and A. T. Kirkpatrick, "Internal Combustion Engines - Applied Thermosciences", $2^{\text {nd }}$ Edition, John Wiley \&Sons, Inc., 2001.

${ }^{6}$ R. Chen, N. Milovanovic, "A computational study into the effect of exhaust gas recycling on homogeneous charge compression ignition combustion in internal combustion engines fuelled with methane", International Journal of Thermal Sciences, 41 (2002) 805-813, 2002.

$7 \mathrm{M}$. Christensen, et al., "The effect of combustion chamber geometry on $\mathrm{HCCl}$ operation", SAE paper 2002-01-0425, 2002.

${ }^{8}$ R. Chen, N. Milovanovic, "A computational study into the effect of exhaust gas recycling on homogeneous charge compression ignition combustion in internal combustion engines fuelled with methane", International Journal of Thermal Sciences, 41 (2002) 805-813, 2002. 